\title{
Ação genotóxica e antiproliferativa de Polygonum punctatum Elliott (Polygonaceae) sobre o ciclo celular de Allium cepa L.
}

\author{
PASTORI, T. ${ }^{1,2^{*}}$; KUHN, A.W. ${ }^{1}$; TEDESCO, M.. ${ }^{1}$ HOFFMANN, C.E. ${ }^{1}$; NEVES, L.A.S. ${ }^{1}$; CANTO-DOROW, T.S. ${ }^{1}$; \\ TEDESCO, S.B. ${ }^{1}$; \\ 'Universidade Federal de Santa Maria/UFSM, Avenida Roraima, s/n, CEP: 97105-900, Camobi, Santa Maria/ \\ RS-Brasil. * tamarapastori@gmail.com; 2Programa de Pós-Graduação em Botânica; Universidade Federal do \\ Rio Grande do Sul, Av. Bento Gonçalves, 9500 prédio 43433, CEP: 91501-970; Porto Alegre/RS
}

RESUMO: A espécie Polygonum punctatum Elliott (Polygonaceae) é amplamente utilizada pela população como planta medicinal. O objetivo deste trabalho é o de avaliar o potencial genotóxico e mutagênico de $P$. punctatum utilizando raízes de bulbos e radículas em sementes germinadas de Allium cepa através do teste in vivo, e realizar comparações da extração do material vegetal por calor (infusões) e extração a frio (extrato). Para isso, foram preparadas dois tipos de soluções, infusões e extratos foliares de $P$. punctatum, em duas concentrações $0,4 \mathrm{~g} \mathrm{~mL}^{-1}$ e $2,4 \mathrm{~g} \mathrm{~mL}^{-1}$. A infusão foi preparada pela adição das folhas secas em água destilada fervente $\left(100^{\circ} \mathrm{C}\right)$, permanecendo por 10 minutos enquanto o extrato foi preparado através da maceração das folhas secas em água destilada fria. Para o teste em $A$. cepa foram utilizados, para cada tratamento, seis grupos de quatro bulbos e seis caixas gerbox com 50 sementes em cada caixa. Duas lâminas para cada tratamento foram obtidas através da técnica de esmagamento das raízes e coradas com orceína acética $2 \%$. Foram contadas 2000 células por grupo de bulbos e 3000 células por grupo de sementes, observando-se a ocorrência de interrupções em metáfases, alterações cromossômicas estruturais, bem como a inibição ou aumento da divisão celular. Os valores do índice mitótico foram calculados e analisados estatisticamente pelo Teste $\mathrm{X}^{2}(\mathrm{p} \leq 0,05)$. Os resultados demonstraram que as infusões e os extratos de folhas apresentaram redução nos valores de índices mitóticos nas concentrações utilizadas em relação ao controle em água destilada. Foram identificadas alterações cromossômicas na divisão celular, tais como pontes anafásicas, em todas as concentrações de infusões e extratos indicando assim que $P$. punctatum possui atividade antiproliferativa e genotóxica.

Palavras-chave: Polygonum punctatum, genotoxicidade, plantas medicinais, Allium cepa.

\begin{abstract}
Genotoxic and antiproliferative action of Polygonum punctatum Elliott (Polygonaceae) on the cell cycle of Allium cepa L. The species Polygonum punctatum Elliott (Polygonaceae) is widely used by the Brazilian population as a medicinal plant. The aims of this study are to evaluate the genotoxic and mutagenic potential of $P$. punctatum, using its root bulbs and rootlets in germinated seeds of Allium cepa by in vivo testing, and to compare the extraction of plant material by heat (infusions) and cold (extract). Thus, two types of solutions - infusions and leaf extracts - of P. punctatum were prepared at the two concentrations of $0.4 \mathrm{~g} \mathrm{ml}^{-1}$ and 2.4 $\mathrm{g} \mathrm{mL}^{-1}$. The infusion was prepared by addition of dry leaves in boiling distilled water $\left(100^{\circ} \mathrm{C}\right)$, remaining for 10 minutes, while the extract was prepared by maceration of dried leaves in cold distilled water. For the A. cepa, we used for each treatment six groups of six bulbs and six seedling boxes with 50 seeds each. Two slides for each treatment were obtained by the technique of crushing the roots, and they were stained with $2 \%$ acetic orcein. For the analysis, 2000 cells per group of bulbs and 3000 cells per group of seeds were counted, and we noted the occurrence of interruptions in the metaphase, chromosomal aberrations, as well as inhibited or increased cell division. The values of the mitotic index were calculated and statistically analyzed by the $x 2$ test $(p \leq 0.05)$. The results showed that the infusions and extracts of leaves showed reduced values of mitotic indices in the concentrations used compared to the control in distilled water. Chromosomal alterations were identified in the cell division, in all concentrations of infusions and extracts, thus indicating that $P$. punctatum has an antiproliferative and genotoxic activity.
\end{abstract}

Key words: Polygonum punctatum, genotoxicity, medicinal plants, Allium cepa. 


\section{INTRODUÇÃO}

O Brasil possui um alto potencial em plantas medicinais e estas são utilizadas na medicina popular para tratamento de diversos sintomas. Apesar dessa ampla utilização pela população, existem poucos estudos científicos na área de genotoxicidade e ação mutagênica destas ervas medicinais, sendo que a segurança e a eficácia destes tratamentos podem estar comprometidas pela escassez de informações essenciais sobre as espécies vegetais. Apesar das ervas medicinais serem muito utilizadas para o tratamento de doenças ou alívio de sintomas, a maioria não foi suficientemente estudada, principalmente quanto à presença de substâncias citotóxicas/mutagênicas em sua composição, decorrentes do próprio metabolismo da planta e que podem causar danos à saúde da população (Fennell et al., 2004; Bagatini et al., 2007).

Os efeitos da genotoxicidade e/ou mutagenicidade podem ser constatados pelo fenômeno da inibição da divisão celular. O índice mitótico e índice de replicação são usados como indicadores de proliferação adequada das células (Gadano et al., 2002), o que pode ser avaliado no teste vegetal in vivo de Allium cepa L. Além desse teste, outros também podem ser utilizados na detecção de efeitos genotóxicos e mutagênicos, como: teste de mutação e recombinação somática (SMART), teste de troca de cromátides irmãs, teste de Ames, teste de mutagênese e recombinogênese em Saccharomyces cerevisae, teste de micronúcleos, teste de aberrações cromossômicas e teste Cometa (Souza, 2005).

O método da aberração cromossômica em raízes de Allium cepa é validado pelo Programa Internacional de Segurança Química (IPCS, WHO) e pelo Programa Ambiental das Nações Unidas (UNEP) como um eficiente teste para análise e monitoramento in situ da genotoxicidade de substâncias ambientais (Cabrera \& Rodriguez 1999; Silva et al. 2004).

As espécies de Polygonum (Polygonaceae) são muito utilizadas para fins medicinais e apresentam grande diversidade de metabólitos secundários, sendo que algumas são ricas em flavonóides, terpenos ou em outras classes de metabólitos (Xiao et al., 2000; Yagi et al., 1994; Furuta et al., 1986). Dentro desse gênero, destacase a espécie Polygonum punctatum Elliott, conhecida popularmente como erva-de-bicho, cataia, acataia, capiçoba, pimenta-do-brejo ou pimenta-da-água (Corrêa 1984). Todas as partes da planta são utilizadas na medicina popular, principalmente como antidisentérica, antisséptica, estomáquica, diurética, antitérmica, anti-reumática, vermífuga e cicatrizante de feridas e úlceras (Who 1989; Martins et al. 1995; Oliveira-Simões et al., 1989). Além disso, esta esoécie também é considerada fortemente emenagoga e abortiva, não sendo recomendada para gestantes (Morgan 1984).

Devido à importância das plantas medicinais na utilização pela população e à escassez de trabalhos que informem a respeito da possível genotoxicidade/mutagenicidade, este estudo objetivou avaliar o potencial genotóxico e mutagênico de $P$. punctatum, utilizando raízes de bulbos e radículas obtidas a partir da germinação de sementes de $A$. cepa através do teste in vivo, e realizar comparações da extração do material vegetal por calor (infusões) e extração a frio (extrato).

\section{MATERIAL E MÉTODOS}

O experimento foi conduzido no Laboratório de Citogenética Vegetal e Genotoxicidade da Universidade Federal de Santa Maria, Santa Maria, Rio Grande do Sul. As partes aéreas de 10 plantas de P. punctatum (erva-de-bicho), incluindo caule, folhas, flores e frutos, foram coletadas e armazenadas em sacos plásticos. As coletas foram realizadas no Campus da Universidade Federal de Santa Maria (UFSM), na cidade de Santa Maria

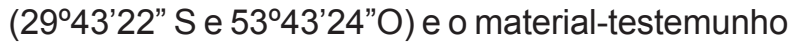
foi identificado e está depositado no herbário SMDB (Santa Maria Departamento de Biologia), do Centro de Ciências Naturais e Exatas (CCNE), da UFSM, sob número de registro SMDB 12.418.

Para o preparo das infusões e dos extratos, foram utilizadas folhas secas em temperatura ambiente $\left(25^{\circ} \mathrm{C}\right)$ e após pesadas para obtenção de soluções em duas concentrações, $0,4 \mathrm{~g} \mathrm{~mL}^{-1}$ e $2,4 \mathrm{~g}$ $\mathrm{mL}^{-1}$. A concentração de $0,4 \mathrm{~g} \mathrm{~mL}^{-1}$ é considerada usual, já que é comumente utilizada pela população no preparo de infusões, já a concentração de $2,4 \mathrm{~g}$ $\mathrm{mL}^{-1}$ é uma solução superconcentrada utilizada para comparações. As infusões foram preparadas colocando-se o material em contato com água destilada fervente $\left(100^{\circ} \mathrm{C}\right)$ durante 10 minutos. Depois de decorrido este tempo, a solução foi filtrada e deixada à temperatura ambiente $\left(25^{\circ} \mathrm{C}\right)$. Os extratos foram preparados através da maceração do material vegetal em contato com água destilada fria (temperatura ambiente de $25^{\circ}$ ) durante 10 minutos, sendo após filtrado e a solução armazenada em temperatura ambiente $\left(25^{\circ} \mathrm{C}\right)$.

Para o teste com bulbos de $A$. cepa foram utilizados seis tratamentos. Para cada tratamento foram utilizados quatro grupos de bulbos como repetições, totalizando 24 bulbos analisados. Os tratamentos utilizados foram: controle negativo em água destilada (T0); infusão na concentração de $0,4 \mathrm{~g} \mathrm{~mL}^{-1}(\mathrm{~T} 1)$; infusão na concentração de $2,4 \mathrm{~g}$

Rev. Bras. PI. Med., Campinas, v.17, n.2, p.186-194, 2015. 
$\mathrm{mL}^{-1}$ (T2); extrato-na concentração de $0,4 \mathrm{~g} \mathrm{~mL}^{-1}(\mathrm{~T} 3)$; extrato na concentração de $2,4 \mathrm{~g} \mathrm{~mL}^{-1}$ (T4) e controle positivo em Glifosato 15\% (T5).

Os bulbos foram enraizados em água destilada durante sete dias e, após, permaneceram em contato com os tratamentos por 24 horas, exceto o controle negativo, que permaneceu na água destilada. Após esse período, as raízes foram coletadas e fixadas em Carnoy modificado (etanol - ácido acético 3:1), onde permaneceram por 24 horas, sendo removidas para frascos contendo álcool $70 \%$ e conservadas no refrigerador em temperatura de $7^{\circ} \mathrm{C}$ até o uso.

$O$ teste realizado com as radículas obtidas da germinação das sementes de $A$. cepa foi composto de cinco tratamentos com seis repetições de 300 sementes (seis caixas gerbox, contendo 50 sementes cada). Os tratamentos utilizados foram: controle negativo em água destilada (T0); infusão na concentração de $0,4 \mathrm{~g} \mathrm{~mL}^{-1}(\mathrm{~T} 1)$; infusão na concentração de $2,4 \mathrm{~g} \mathrm{~mL}^{-1}$ (T2); extrato na concentração de $0,4 \mathrm{~g} \mathrm{~mL}^{-1}$ (T3); extrato na concentração de $2,4 \mathrm{~g} \mathrm{~mL}^{-1}$ (T4).

As sementes foram colocadas em caixas gerbox, contendo 50 sementes cada e duas camadas de papel filtro, embebidos em $2 \mathrm{~mL}$ de água destilada e após foram colocadas em germinador B.O.D, com temperatura de $20^{\circ}$ e fotoperíodo de 12 horas. Após o primeiro dia, quando as sementes ainda não haviam germinado, iniciou-se o período de tratamento com as soluções vegetais obtidas previamente, adicionando-se $1 \mathrm{~mL}$ por dia a cada caixa gerbox, exceto para o controle negativo, onde as sementes permaneceram em água destilada. Após 12 dias, as radículas foram coletadas e fixadas em Carnoy modificado (etanolácido acético 3:1), onde permaneceram por 24 horas, sendo igualmente removidas para frascos contendo álcool $70 \%$ e conservadas no refrigerador em temperatura de $7^{\circ} \mathrm{C}$ até o uso.

Para o preparo das lâminas foram utilizadas pontas de duas raízes por bulbo e duas radículas por cada caixa gerbox escolhidas aleatoriamente. As mesmas foram hidrolisadas em ácido clorídrico $(\mathrm{HCl}) 1 \mathrm{~N}$ por 5 minutos, lavadas em água destilada e coradas com orceína acética $2 \%$. As lâminas foram confeccionadas pela técnica de esmagamento (Guerra \& Souza, 2002) e examinadas observandose as fases do ciclo celular, com auxílio de microscópio óptico com a objetiva de 40X. Foram utilizadas duas raízes por bulbo e duas radículas por caixa gerbox. De cada raiz foi elaborada uma lâmina e foram contadas 250 células por lâmina, somando 500 células em cada repetição. Sendo assim, a análise realizada com raízes de bulbos somou um total de 2000 células por tratamento e com radículas obtidas a partir da germinação das sementes somou 3000 células por tratamento. Foram calculados os valores médios do número de células de cada uma das fases do ciclo celular de A. cepa e foi determinado o índice mitótico (IM), a partir do número de células em divisão dividido pelo número total de células observadas multiplicado por cem (Pires et al., 2001), bem como a observação de ocorrência de alterações cromossômicas.

A análise estatística dos dados foi realizada pelo teste $X^{2}(p \leq 0,05)$, utilizando-se o programa estatístico BioEstat 3.0 (Ayres 2003).

\section{RESULTADOS E DISCUSSÃO}

As Tabelas 1 e 2 são referentes às análises com os bulbos de $A$. cepa, já as tabelas 3 e 4 são relacionadas aos resultados observados em radículas obtidas a partir da germinação de sementes de $A$. cepa. As Tabelas 1 e 3 apresentam os números totais de células analisadas, células nas diferentes fases do ciclo celular, bem como células que foram observadas em interfase, além de mostrar os valores do Índice Mitótico (IM) e o número total de células em divisão de cada tratamento. Já as Tabelas 2 e 4 mostram os números totais de células em divisão, as alterações ocorridas durante a divisão celular e as porcentagens das células com alterações cromossômicas.

Os resultados obtidos (Tabela 1) nas análises referentes aos tratamentos realizados nos bulbos de A. cepa mostram os índices mitóticos do controle em água destilada diferiram significativamente de todos os tratamentos utilizados. O controle em Glifosato $15 \%$ também apresentou diferença significativa quando comparado com os demais tratamentos (infusão de $0,4 \mathrm{~g} \mathrm{~mL}^{-1}-X^{2}=18.179$, infusão de $2,4 \mathrm{~g}$ $\mathrm{mL}^{-1}-X^{2}=3.156$, extrato $0,4 \mathrm{~g} \mathrm{~mL}^{-1}-\mathrm{X}^{2}=22.065$ e do extrato $0,4 \mathrm{~g} \mathrm{~mL}^{-1}-X^{2}=15.509$ ). $O$ tratamento em infusão de $0,4 \mathrm{~g} \mathrm{~mL}^{-1}$ diferiu significativamente da infusão de $2,4 \mathrm{~g} \mathrm{~mL}^{-1}\left(X^{2}=6.473\right)$ e do extrato $0,4 \mathrm{~g}$ $\mathrm{mL}^{-1}(\mathrm{~T} 3)\left(X^{2}=74.353\right)$, não diferindo do extrato $2,4 \mathrm{~g}$ $\mathrm{mL}^{-1}\left(X^{2}=295.944\right)$. $O$ tratamento com infusão de $2,4 \mathrm{~g}$ $\mathrm{mL}^{-1}$ diferiu significativamente dos extratos $0,4 \mathrm{~g} \mathrm{~mL}^{-1}$ $\left(X^{2}=40.704\right)$ e $2,4 \mathrm{~g} \mathrm{~mL}^{-1}\left(X^{2}=4.869\right)$. Já o tratamento com extrato $0,4 \mathrm{~g} \mathrm{~mL}^{-1}$ diferiu significativamente do extrato $2,4 \mathrm{~g} \mathrm{~mL}^{-1}\left(\mathrm{X}^{2}=69.515\right)$.

A Tabela 1 mostra os valores dos índices mitóticos, que foram $22,7 \%$ no controle em água destilada, $1,90 \%$ na infusão de $0,4 \mathrm{~g} \mathrm{~mL}^{-1}, 3,20 \%$ na infusão $2,4 \mathrm{~g} \mathrm{~mL}^{-1}, 8,30 \%$ no extrato de $0,4 \mathrm{~g}$ $\mathrm{mL}^{-1}, 2,04 \%$ no extrato de $2,4 \mathrm{~g} \mathrm{~mL}^{-1}$. Estes dados mostram que ocorreu uma diminuição no índice mitótico, a partir da água destilada, considerada o controle negativo até as diferentes concentrações dos extratos e das infusões de P. punctatum, o que representa o potencial antiproliferativo destes tratamentos no teste in vivo em bulbos de $A$. cepa.

Rev. Bras. PI. Med., Campinas, v.17, n.2, p.186-194, 2015. 
Quanto ao número de células em divisão, o controle negativo em água, apresentou o maior número de células em divisão (370), seguido pelo extrato na concentração $2,4 \mathrm{~g} \mathrm{~mL}^{-1}$ apresentou o segundo maior número de células em divisão (153) sendo predominantemente, células em prófase. A infusão na concentração de $0,4 \mathrm{~g} \mathrm{~mL}-1$ apresentou o menos número de células em divisão (37) e o menor índice mitótico (1,90\%).

Na Tabela 2, são mostradas as alterações do ciclo celular para células obtidas a partir das raízes emitidas por bulbos de $A$. cepa. As alterações mitóticas encontradas foram de seis tipos: micronúcleo (Fig. 1-B), pontes anafásicas (Fig. 1-C), pontes anafásicas com quebras cromossômicas (Fig.1-C), cromossomo atrasado (Fig. 1-D), divisão celular desorganizada (Fig. 1-E) e quebra cromossômica (Fig. 1-F). O controle com Glifosato $15 \%$ foi o que apresentou maior número de células com alterações (47\%), seguido pelo extrato preparado por infusão na concentração de $0,4 \mathrm{~g} \mathrm{~mL}^{-1}$ (37,8\%), infusão $2,4 \mathrm{~g} \mathrm{~mL}^{-1}(33,8 \%)$, extrato $0,4 \mathrm{~g} \mathrm{~mL}^{-1}$ $(29,4 \%)$ e finalmente o extrato $2,4 \mathrm{~g} \mathrm{~mL}^{-1}(5 \%)$.

Quando utilizadas infusões nas radículas de plântulas de $A$. cepa obtidas a partir da germinação de sementes, a concentração de $0,4 \mathrm{~g}$ $\mathrm{mL}^{-1}$ apresentou maior atividade antiproliferativa (IM=1,90\%) que a concentração mais elevada $2,4 \mathrm{~g}$ $\mathrm{mL}^{-1}(\mathrm{IM}=8,30 \%)$. Já quando foram utilizados os extratos das mesmas concentrações, $0,4 \mathrm{~g} \mathrm{~mL}^{-1} \mathrm{e}$ $2,4 \mathrm{~g} \mathrm{~mL}^{-1}$, observou-se que a concentração mais elevada apresentou maior atividade antiproliferativa $(\mathrm{IM}=2,04 \%)$ que a concentração usual $(\mathrm{IM}=3,20 \%)$.
$\mathrm{Na}$ Tabela 3 estão apresentados os resultados obtidos das radículas de plântulas obtidas a partir da germinação das sementes de A. cepa. Pode-se observar que o índice mitótico (IM) apresentou diferença significativa em todos os tratamentos utilizados, água destilada,a infusão de $0,4 \mathrm{~g} \mathrm{~mL}^{-1}$, a infusão de $2,4 \mathrm{~g} \mathrm{~mL}^{-1}$, o extrato $0,4 \mathrm{~g} \mathrm{~mL}^{-1}$ e o extrato $2,4 \mathrm{~g} \mathrm{~mL}^{-1}$. Já o tratamento com infusão de $0,4 \mathrm{~g} \mathrm{~mL}^{-1}$ diferiu significativamente da infusão de $2,4 \mathrm{~g} \mathrm{~mL}^{-1}\left(X^{2}=1.086\right)$, do extrato $0,4 \mathrm{~g} \mathrm{~mL}^{-1}\left(X^{2}=\right.$ $45.558)$ e do extrato $2,4 \mathrm{~g} \mathrm{~mL}^{-1}\left(X^{2}=2.622\right)$. A infusão $2,4 \mathrm{~g} \mathrm{~mL}^{-1}$ diferiu significativamente dos extratos $0,4 \mathrm{~g} \mathrm{~mL}^{-1}\left(X^{2}=59.943\right)$ mas não houve diferença significativa quando comparado com o extrato $2,4 \mathrm{~g}$ $\mathrm{mL}^{-1}\left(X^{2}=0.334\right)$. Po fim, o tratamento com extrato $0,4 \mathrm{~g} \mathrm{~mL}^{-1}$ diferiu significativamente do extrato $2,4 \mathrm{~g}$ $\mathrm{mL}^{-1}\left(\mathrm{X}^{2}=68.635\right)$.

Os valores dos Índices Mitóticos foram $13,9 \%$ no controle em água destilada, $5,18 \%$ na infusão de $0,4 \mathrm{~g} \mathrm{~mL}^{-1}, 4,56 \%$ no infusão $2,4 \mathrm{~g} \mathrm{~mL}^{-1}$, $10,41 \%$ no extrato de $0,4 \mathrm{~g} \mathrm{~mL}^{-1}, 4,24 \%$ no extrato de $2,4 \mathrm{~g} \mathrm{~mL}^{-1}$. Como observado, o IM diminuiu de acordo com o aumento das concentrações das infusões e dos extratos, mostrando que $P$. punctatum apresenta atividade antiproliferativa no ciclo celular de radículas obtidas de sementes de $A$. cepa.

As alterações da divisão celular encontradas para raízes de $A$. cepa tratadas com infusões e extratos de $P$. punctatum foram de 7 tipos: micronúcleo e divisão celular desorganizada com cromossomo perdido (Fig. 2-B), quebra cromossômica, cromossomo atrasado, pontes anafásicas (Fig. 2-C), quebra cromossômica e

TABELA 1. Dados obtidos da análise das raízes emitidas a partir de bulbos de Allium cepa. Número total de células, células no ciclo celular (interfase, prófase, metáfase, anáfase e telófase), índices mitóticos e células em interfase tratadas com diferentes concentrações de infusões e extratos de Polygonum punctatum, em seis tratamentos diferentes e quatro grupos de bulbos como repetições para cada tratamento, totalizando 2000 células analisadas por tratamento.

\begin{tabular}{|c|c|c|c|c|c|c|}
\hline \multicolumn{3}{|l|}{ Análises } & \multicolumn{2}{|c|}{ Infusão } & \multicolumn{2}{|c|}{ Extrato } \\
\hline \multirow{2}{*}{ Tratamento } & Controle (-) & Controle (+) & {$\left[0,4 \mathrm{~g} \mathrm{~mL}^{-1}\right]$} & {$\left[2,4 \mathrm{~g} \mathrm{~mL}^{-1}\right]$} & {$\left[0,4 \mathrm{~g} \mathrm{~mL}^{-1}\right]$} & {$\left[2,4 \mathrm{~g} \mathrm{~mL}^{-1}\right]$} \\
\hline & TO & T5 & $\mathrm{T1}$ & T2 & T3 & T4 \\
\hline Número Total de Células & 2000 & 2000 & 2000 & 2000 & 2000 & 2000 \\
\hline Células em Interfase & 1630 & 1917 & 1963 & 1938 & 1847 & 1960 \\
\hline \multirow{3}{*}{$\begin{array}{l}\text { Células } \\
\text { Divisão }\end{array}$} & 334 & 23 & 32 & 59 & 151 & 37 \\
\hline & 10 & 30 & 0 & 0 & 1 & 0 \\
\hline & 9 & 17 & 1 & 1 & 1 & 2 \\
\hline Telófase & 17 & 13 & 4 & 2 & 0 & 1 \\
\hline Índice Mitótico & $22,7^{\mathrm{a}}$ & $4,33^{c}$ & $1,90^{f}$ & $3,20^{d}$ & $8,30^{\circ}$ & 2,04 \\
\hline
\end{tabular}

Todas as médias diferem significativamente ao nível de 5\%, pelo teste $X^{2}$. Médias seguidas da mesma letra não diferiram entre si. Tratamentos: controle negativo em água destilada (T0); infusão na concentração de $0,4 \mathrm{~g} \mathrm{~mL}-1$ (T1); infusão na concentração de $2,4 \mathrm{~g}$ mL-1 (T2); extrato na concentração de $0,4 \mathrm{~g} \mathrm{~mL}-1$ (T3); extrato na concentração de 2,4g mL-1 (T4) e controle positivo em Glifosato $15 \%$ (T5). Tempo de tratamento: Controle negativo T0 $=0 \mathrm{~h}$ (t zero), Tratamentos: T1, T2, T3, T4 e controle positivo T5 $=24 \mathrm{~h}$. 
TABELA 2. Alterações mitóticas obtidas na análise das raízes emitidas a partir de bulbos de Allium cepa tratadas com diferentes concentrações de infusões e extratos de Polygonum punctatum, em seis tratamentos diferentes, com quatro grupos de bulbos como repetições para cada tratamento, totalizando 2000 células analisadas por tratamento.

\begin{tabular}{|c|c|c|c|c|c|c|c|}
\hline \multicolumn{2}{|l|}{ Análises } & \multicolumn{4}{|c|}{ Infusão } & \multicolumn{2}{|l|}{ Extrato } \\
\hline \multirow{2}{*}{\multicolumn{2}{|c|}{ Tratamento }} & Controle(-) & Controle (+) & {$\left[0,4 \mathrm{~g} \mathrm{~mL}^{-1}\right]$} & {$\left[2,4 \mathrm{~g} \mathrm{~mL}^{-1}\right]$} & {$\left[0,4 \mathrm{~g} \mathrm{~mL}^{-1}\right]$} & {$\left[2,4 \mathrm{~g} \mathrm{~mL}^{-1}\right]$} \\
\hline & & Tо & T5 & T1 & T2 & T3 & T4 \\
\hline \multicolumn{2}{|c|}{ Número de células em divisão } & 370 & 83 & 37 & 62 & 153 & 40 \\
\hline \multirow{8}{*}{$\begin{array}{l}\text { Alterações } \\
\text { celulares }\end{array}$} & Quebra & - & 15 & 1 & - & - & - \\
\hline & atrasado & - & 2 & - & 1 & 2 & 1 \\
\hline & Pontes anafásicas & - & 6 & - & - & - & - \\
\hline & Pontes anafásicas & & & & & & \\
\hline & com quebras & - & 8 & - & 1 & - & - \\
\hline & cromossômicas & & & & & & \\
\hline & Micronúcleos & - & 0 & 13 & 19 & 43 & - \\
\hline & $\begin{array}{l}\text { Divisão celular } \\
\text { desorganizada }\end{array}$ & - & 8 & - & - & - & 1 \\
\hline \multicolumn{2}{|c|}{ Total de células com Alterações } & - & 39 & 14 & 21 & 45 & 2 \\
\hline \multicolumn{2}{|c|}{ Alterações celulares (\%) } & 0 & $47,0 \%$ & $37,8 \%$ & $33,8 \%$ & $29,4 \%$ & $5,0 \%$ \\
\hline
\end{tabular}

Tempo de tratamento: Controle negativo T0= 0h (t zero), Tratamentos: T1, T2, T3, T4 e controle positivo T5 = 24h. Tratamentos: controle negativo em água destilada (T0); infusão na concentração de $0,4 \mathrm{~g} \mathrm{~mL}-1$ (T1); infusão na concentração de $2,4 \mathrm{~g} \mathrm{~mL} \mathrm{~L}^{-1}$ (T2); extrato na concentração de $0,4 \mathrm{~g} \mathrm{~mL}^{-1}(\mathrm{~T} 3)$; extrato na concentração de $2,4 \mathrm{~g} \mathrm{~mL}^{-1}$ (T4) e controle positivo em Glifosato $15 \%$ (T5).

TABELA 3. Dados obtidos da análise das raízes emitidas a partir de sementes de Allium cepa. tratadas com diferentes concentrações de infusões e extratos de Polygonum punctatum, em cinco tratamentos diferentes e seis grupos de 50 sementes cada como repetições para cada tratamento, totalizando 3000 células analisadas por tratamento.

\begin{tabular}{|c|c|c|c|c|c|c|}
\hline \multicolumn{3}{|l|}{ Análises } & \multicolumn{2}{|l|}{ Infusão } & \multicolumn{2}{|c|}{ Extrato } \\
\hline \multirow{2}{*}{\multicolumn{2}{|c|}{ Tratamento }} & Controle (-) & {$\left[0,4 \mathrm{~g} \mathrm{~mL}^{-1}\right]$} & {$\left[2,4 \mathrm{~g} \mathrm{~mL}^{-1}\right]$} & {$\left[0,4 \mathrm{~g} \mathrm{~mL}^{-1}\right]$} & {$\left[2,4 \mathrm{~g} \mathrm{~mL}^{-1}\right]$} \\
\hline & & TO & T1 & T2 & T3 & T4 \\
\hline \multicolumn{2}{|c|}{ Número total de células } & 3000 & 3000 & 3000 & 3000 & 3000 \\
\hline \multicolumn{2}{|c|}{ Células em interfase } & 2634 & 2852 & 2869 & 2717 & 2812 \\
\hline \multirow{4}{*}{$\begin{array}{c}\text { Células em } \\
\text { divisão }\end{array}$} & Prófase & 165 & 88 & 69 & 62 & 62 \\
\hline & Metáfase & 80 & 26 & 26 & 31 & 31 \\
\hline & Anáfase & 73 & 14 & 15 & 15 & 15 \\
\hline & Telófase & 48 & 20 & 21 & 24 & 14 \\
\hline \multicolumn{2}{|c|}{ Índice Mitótico } & $13,90 \mathrm{a}$ & $5,18 \mathrm{c}$ & $4,56^{d}$ & $10,41^{\mathrm{b}}$ & 4,24 \\
\hline
\end{tabular}

Todas as médias diferem significativamente ao nível de $5 \%$, pelo teste $X^{2}$. Médias seguidas da mesma letra não diferiram entre si. Tratamentos: controle negativo em água destilada (T0); infusão na concentração de $0,4 \mathrm{~g} \mathrm{~mL}-1$ (T1); infusão na concentração de $2,4 \mathrm{~g} \mathrm{~mL}-1$ (T2); extrato na concentração de 0,4g mL-1 (T3); extrato na concentração de 2,4g mL-1 (T4). Tempo de tratamento: Controle negativo T0= 0h (t zero), Tratamentos: $\mathrm{T} 1, \mathrm{~T} 2, \mathrm{~T} 3, \mathrm{~T} 4=24 \mathrm{~h}$ 

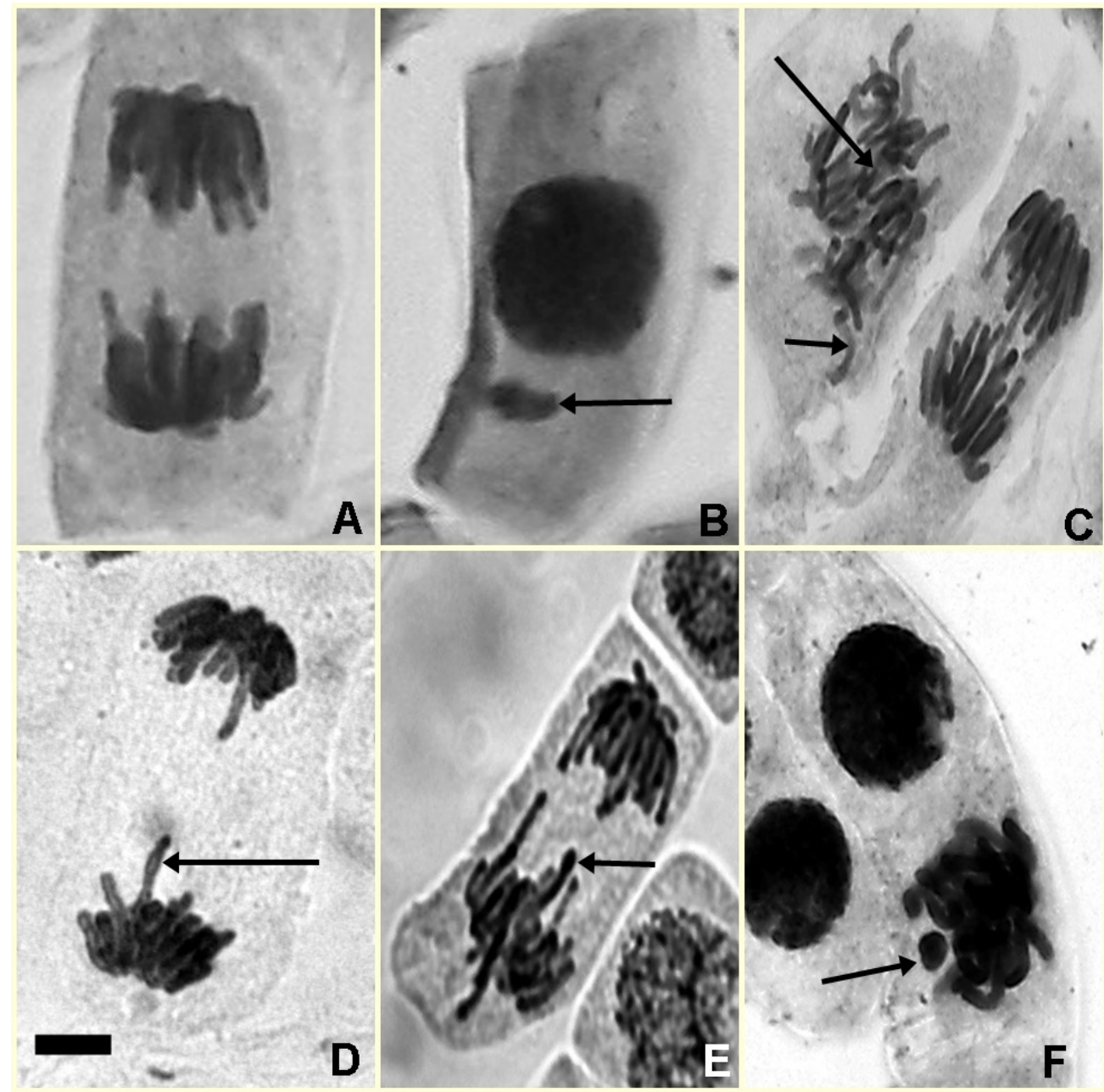

FIGURA 1. Células obtidas a partir das raízes emitidas de bulbos de Allium cepa tratadas com diferentes concentrações de infusões e extratos de Polygonum punctatum, em seis tratamentos diferentes e com setas indicativas nas alterações. A) Telófase regular (T0= água destilada). B) Micronúcleo ( 1 1=Infusão 0,4g mL-1). C) Ponte anafásica com quebra cromossômica (T2= Infusão 2,4g mL-1). D) Cromossomo atrasado (T3= Extrato 0,4 $\mathrm{g} \mathrm{mL}^{-1}$ ) E) Cromossomo atrasado (T4= Extrato 2,4 $\mathrm{g} \mathrm{mL}^{-1}$ ). F) Quebra cromossômica. (T5= Glifosato 15\%). Observações realizadas em microscópio óptico com aumento de 40x.

cromossomo perdido (Fig. 2-D) e divisão celular desorganizada (Fig. 2-E). A infusão na concentração de $2,4 \mathrm{~g} \mathrm{~mL}^{-1}$ apresentou maior porcentagem de células com alterações.

Os dados obtidos nesse trabalho mostram que a espécie $P$. punctatum possui atividade genotóxica, mutagênica e antiproliferativa em testes in vivo realizados com $\mathrm{A}$. cepa. O uso de ensaios biológicos para avaliação da bioatividade de extratos, frações e compostos isolados de plantas tem sido frequentemente incorporado à identificação e ao monitoramento de substâncias potencialmente tóxicas (Noldin et al., 2003). Segundo Fiskesjö (1994), mesmo que o metabolismo vegetal seja diferente do metabolismo animal, o sistema teste de $A$. cepa é um excelente parâmetro de análise citotóxica, além disso observações da ocorrência de alterações cromossômicas no ciclo celular de $A$. cepa tem sido usada como indicativo para prevenir a população humana sobre o consumo do produto (Vicentini et al., 2001).

A avaliação das infusões e dos extratos de $P$. punctatum através do teste de $A$. cepa, demonstrou que, quando comparados ao controle em água destilada, houve uma inibição significativa da divisão celular, ocasionando o decréscimo nos valores dos IM (Tabelas 1 e 3 ), em todas as concentrações analisadas, indicando atividade antiproliferativa dos extratos das folhas dessa planta medicinal.

A infusão na concentração de $0,4 \mathrm{~g}$ $\mathrm{mL}^{-1}$, aplicada nas raízes de bulbos de $A$. cepa proporcionou maior atividade antiproliferativa (IM=1,9\%) quando comparada com a concentração de $2,4 \mathrm{~g} \mathrm{~mL}^{-1}(\mathrm{IM}=3,2 \%)$. O extrato apresentou maior atividade antiproliferativa com o aumento da concentração, sendo que a menor concentração 
TABELA 4. Alterações mitóticas obtidas na análise das radículas emitidas a partir de sementes de Allium cepa. por tratamento tratadas com diferentes concentrações de infusões e extratos de Polygonum punctatum, em cinco tratamentos diferentes e seis grupos de 50 sementes cada como repetições para cada tratamento, totalizando 3000 células analisadas por tratamento.

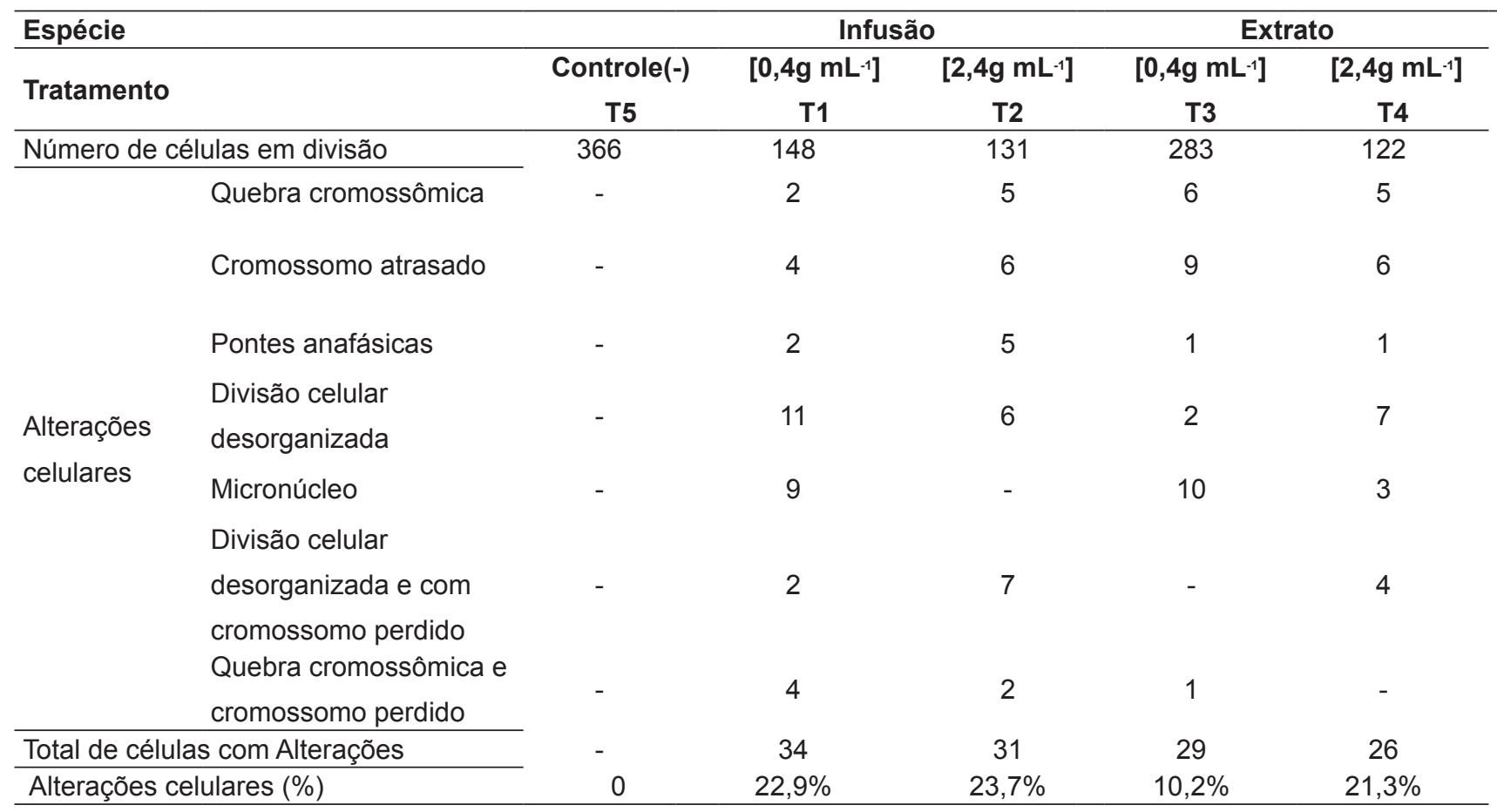

Tratamentos: controle negativo em água destilada (T0); infusão na concentração de 0,4g mL-1 (T1); infusão na concentração de 2,4g mL-1 (T2); extrato na concentração de $0,4 \mathrm{~g} \mathrm{~mL}-1$ (T3); extrato na concentração de 2,4g mL-1 (T4). Tempo de tratamento: Controle negativo T0= Oh (t zero), Tratamentos: T1, T2,T3, T4 = 24h.

promoveu menor inibição da divisão celular $(\mathrm{IM}=8,30 \%)$ que a concentração de $2,4 \mathrm{~g} \mathrm{~mL}^{-1}$ (IM= $2,04 \%)$.

Trabalhos semelhantes têm sido realizados com o teste A. cepa. Estudo publicado por Frescura et al. (2012) mostrou que tanto folhas quanto cascas de Luehea divaricata Mart. apresentam efeitos antiproliferativos capazes de inibir a divisão celular no ciclo celular de $A$. cepa. Já Knoll et al. (2006) estudaram o potencial genotóxico de diferentes populações de Pterocaulon polystachyum DC., mostrando sua capacidade antiproliferativa, utilizando o teste de $A$. cepa. Durante o ensaio, a inibição da divisão celular aumentou de forma dependente da concentração. Resultados semelhantes foram obtidos por Fachinetto et al. (2007) utilizando o teste de $A$. cepa para analisar infusões de Achyrocline satureioides (Lam.) DC. Além disso, foi observado um aumento da ação antiproliferativa de $A$. satureioides, dependendo do tempo de armazenamento da planta. Estes resultados corroboram os dados obtidos no presente artigo, e indicam que análises para identificação de compostos secundários presentes infusões de plantas medicinais, seriam importantes para futuras comparações.

Na Tabela 1 observou-se, com o aumento da concentração das infusões, o aumento nos valores do índice mitótico e, ao contrário, nos extratos, com o aumento da concentração houve inibição do índice mitótico utilizando-se o sistema teste dos bulbos de $A$. cepa. No entanto, a análise com radículas de plântulas provenientes de sementes de $A$. cepa não demonstrou esse padrão, talvez essa diferença possa ser atribuída ao fato de que o sistema de bulbos permite a imersão total dos mesmos nas substâncias testadas, tornando o teste mais sensível (Fiskejo, 1993). O fato de ocorrer aumento dos valores do índice mitótico com o aumento da concentração nas infusões e não nos extratos, pode ser atribuído às diferentes formas de preparo e extração dos compostos presentes nas folhas.

Na Figura 1 pode-se observar a ocorrência de células com micronúcleos provenientes de pontas de raízes tratadas com infusão de $0.4 \mathrm{~g} \mathrm{~mL}$ de $P$. punctatum e cromossomo atrasado devido ao tratamento com a mesma concentração, porém preparado sob a forma de extrato. Essas células aberrantes demonstram claramente que os extratos provenientes das folhas de $P$. punctatum possuem atividade genotóxica. Segundo estudo realizado por Bagatini et al. (2009), as infusões de Solidago microglossa DC., em várias concentrações e em

Rev. Bras. PI. Med., Campinas, v.17, n.2, p.186-194, 2015. 


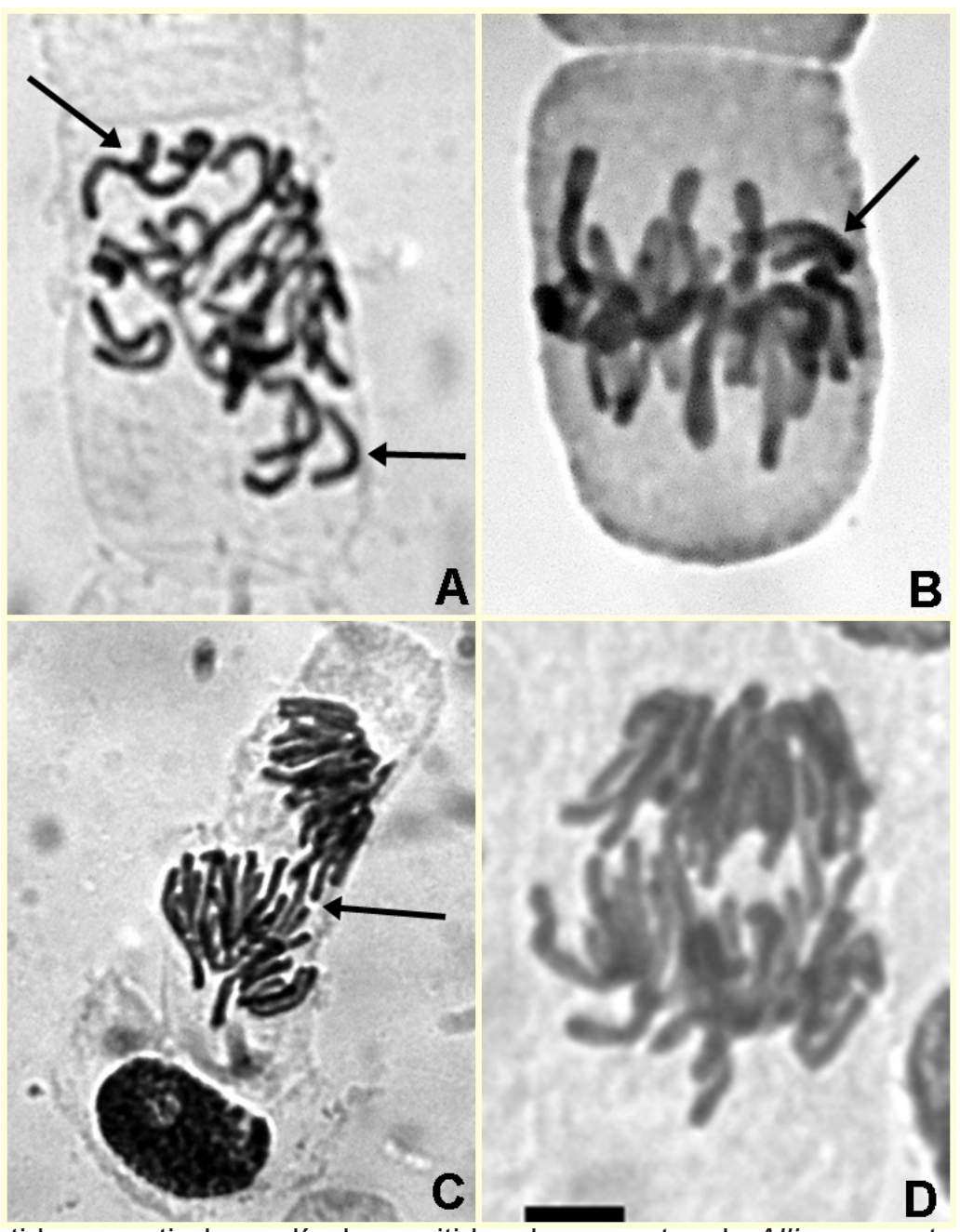

FIGURA 2. Células obtidas a partir das radículas emitidas de sementes de Allium cepa tratadas com diferentes concentrações de infusões e extratos de Polygonum punctatum, em cinco tratamentos diferentes e com setas indicativas nas alterações. A) Divisão celular desorganizada com cromossomo perdido ( $T 1=$ Infusão $0,4 \mathrm{~g} \mathrm{mL-}$ 1); B) Quebra cromossômica e cromossomo perdido ( $\mathrm{T} 3=$ Extrato 0,4g mL-1); C) Ponte anafásica (T2= Infusão 2,4g mL-1); D) Divisão celular desorganizada com cromossomo perdido (T4= - Extrato 2,4g mL-1). Observações realizadas em microscópio óptico com aumento de 40x.

diferentes populações no teste do sistema $A$. cepa, também mostraram a existência de atividade antiproliferativa e citotóxica da espécie.

Fachinetto \& Tedesco (2009) demonstraram que extratos aquosos de Baccharis trimera (Less.) DC. e B. Articulata (Lam.) Pers. apresentaram inibição da divisão celular na concentração usual de $15 \mathrm{~g} / \mathrm{mL}^{-1}$, bem como alterações celulares, indicando a ocorrência de atividade antiproliferativa e mutagênica dos extratos. $O$ trabalho realizado por Souza et al. (2010) mostrou que Artemisia velotorum Lamotte apresenta um aumento da atividade antiproliferativa sobre o ciclo celular de bulbos de A. cepa conforme o aumento da concentração das infusões. Estes trabalhos corroboram os dados obtidos com P. punctatum e mostram que muitas das plantas medicinais são pouco investigadas e, consequentemente, seu potencial genotóxico e mutagênico não é conhecido. Nesse sentido, o teste de $A$. cepa tem se mostrado uma técnica útil para o conhecimento dessas plantas, contribuindo para o uso seguro na medicina popular.

A partir dos resultados deste trabalho conclui-se que, tanto para raízes de bulbos como radículas obtidas a partir da germinação de sementes de $A$. cepa, as soluções preparadas por infusão e por extratos de $P$. punctatum possuem capacidade antiproliferativa, mutagênica e genotóxica dependendo das concentrações e forma de preparo utilizada. $O$ uso desta espécie medicinal por parte da população deve ser cuidadoso. Este estudo configura o início das pesquisas e mais estudos são necessários para estabelecer a concentração segura para a utilização das infusões e extratos de $P$. punctatum na medicina popular. Além disso, análises complementares principalmente 
para a investigação dos componentes químicos presentes nas infusões e extratos, bem como análises cromatográficas são necessárias.

\section{REFERÊNCIAS}

AYRES, M. Bioestat 3.0: aplicações estatísticas nas áreas das ciências biológicas e médicas. Belém: Sociedade Civil Mamirauá, Brasília: CNPq, 2003. 290p.

BAGATINI, M.D. et al. Uso do sistema de Allium cepa como bioindicador de genotoxidade de infusões de plantas medicinais. Revista Brasileira de Farmacognosia, v.17, n.3, p.444-447, 2007.

CABRERA, G.L.; RODRIGUEZ, D.M.G. Genotoxicity of soil from farmland irrigated with wastewater using three plant bioassays. Mutation Research, v.426, p.211-214, 1999.

CORREAA, M.P. Dicionário das Plantas Úteis do Brasil e das Exóticas Cultivadas, Vols I-VI, IBDF, Ministério da Agricultura, Rio de Janeiro. 1984.

FACHINETTO, J.M.; TEDESCO, S.B. Anti-proliferative effect of infusions of Achyrocline satureioides on the Allium cepa cell cycle. Brazilian Journal of Pharmacognosy, v.17, p.49-54, 2007.

FACHINETTO, J.M. et al. Atividade antiproliferativa e mutagênica dos extratos aquosos de Baccharis trimera (Less.) A. P. de Candolle e Baccharis articulata (Lam.) Pers. (Asteraceae) sobre o sistema teste de Allium cepa. Revista Brasileira de Plantas Medicinais, v.11, n.4, p.360-367, 2009.

FENNEL, C.W. et al. Assessing African medicinal plants for efficacy and safety: agricultural and storage practices. Journal of Ethnopharmacology, v.95, n.2-3, p.113121, 2004.

FISKESJO, G. The Allium test. In: Wastewater monitoring. Environmental Toxicology and Water Quality, v.8, p.291-298, 1993.

FISKESJÖ, G. Allium Test II: Assessment of chemical's genotoxic potential by recording aberrations in chromosomes and cell divisions in root tips of Allium cepa L. Environmental Toxicology and Water Quality,v.9, p.235-41, 1994.

FRESCURA, V.D.; LAUGHINGHOUSE IV, H.D.; TEDESCO, S.B. Antiproliferative effect of the tree and medicinal species Luehea divaricata on the Allium cepa cell cycle. Caryologia (Firenze), v. 65, p. 27-33, 2012.

FURUTA, T. et al. Polygonolide, an isocoumarin from Polygonum hydropiper possessing anti-inflammatory activity. Phytochemistry, n.25, p.517- 520, 1986.

GADANO, A. et al. In vitro genotoxic evaluation of the medicinal plant Chenopodium ambrosioides. L. Journal of Ethnopharmacology, v.81, p.11-16, 2002.
GUERRA, M.; SOUZA, M.J. Como observar cromossomos: um guia de técnicas em citogenética vegetal, animal e humana. Ribeirão Preto: FUNPEC, 2002. 191p.

KNOLL, M.F. et al. Effects of Pterocaulon polystachyum DC. (Asteraceae) on onion (Allium cepa) root-tip cells. Genetics and Molecular Biology, v.29, p.539-542, 2006.

OLIVEIRA-SIMÕES, C.M. et al. Pharmacological investigation on Polygonum punctatum Elliott (=P. acre H.B.K.) extracts. Part I. Tests in vivo. J Pharm Belg v.p. 275-284, 1989.

MARTINS, E.R, CASTRO, D.M, CASTELLANI, D.C, DIAS, J.E. Plantas Medicinais, Imprensa Universitária, UFV, Viçosa, p. 117-118, 1995.

MORGAN, R. Plantas medicinais. São Paulo: Hemus, 1984. 555 p.

NOLDIN, V.F. et al. Composição química e atividade biológica de Cynara scolymus L. cultivada no Brasil. Química Nova, v.26, n.3, p.331-334, 2003.

PIRES, N.M., et al. Efeito do extrato aquoso de leucena sobre o desenvolvimento, índice mitótico e atividade da peroxidase em plântulas de milho. Revista Brasileira de Fisiologia Vegetal, v.13, n.1, p.55-65, 2001.

SILVA, C.R, et al. Absence of mutagenic and citotoxic potentiality of senna (Cassia angustifolia Vahl.) evaluated by microbiological tests. Revista Brasileira de Farmacognosia, v.14, p.1-3, 2004.

SIMÕES, C.M.O.; MENTZ, LA.; SCHENKEL, J.R.; IRGANG, B.E.; STEHMANN, J.R. Plantas da medicina popular no Rio Grande do Sul. Porto Alegre, Editora da Universidade Federal do Rio Grande do Sul, 1986.

SOUZA, L.F.B. et al. Genotoxic potential of aqueous extracts of Artemisia verlotorum on the cell cycle of Allium cepa. International Journal of Environmental Studies, v.67, n.6, p.871-877, 2010.

SOUZA, S.A.M. Biotestes na avaliação da fitotoxicidade de extratos aquosos de plantas medicinais nativas do Rio Grande do Sul. 2005. 89p. Monografia de Conclusão de Curso (Ciências Biólogicas) - Instituto de Biologia, Universidade Federal de Pelotas, Rio Grande do Sul.

VICENTINI, V.E.P. et al. Averrhoa carambola L., Syzygium cumini (L.) Skeels and Cissus sicyoides L.: medicinal herbal tea effects on vegetal and animal test systems. Acta Scientiarum, v.23, p.593-598, 2001.

WHO-World Health Organization. Medicinal Plants in China, Western Pacific Series n. 2, p. 227- 229, 1989.

$\mathrm{XIAO}, \mathrm{K}$. et al. Stilbene glycoside sulfates from Polygonum cuspidatum. Journal of Natural Producs, v.63, p.13731376, 2000.

YAGI, A. et al. Antioxidative sulfated fl avonoids in leaves of Polygonum hydropiper. Phytochemistry, v.35, p.885887, 1994. 